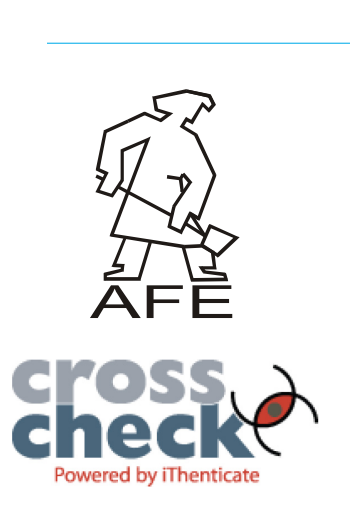

\title{
Management of Assortment Inventory Groups in Selected Foundry
}

\author{
J. Szymszal *, M. Kuczyńska-Chałada, J. Król \\ Production Engineering Department, Silesian University of Technology, 8 Krasińskiego St., 40-019 Katowice, Poland \\ *Corresponding author. E-mail address: jan.szymszal@polsl.pl
}

Received 27.04.2015; accepted in revised form 29.05.2015

\begin{abstract}
As experience shows the practical, reliable assessment and optimisation of total costs of logistical processes implemented in supply chains of foundry plants is a quite complex and complicated process, because it requires to enclose all, without exception, performed actions, including them in various reference cross-sections, systematic activities and finally transforming them in a totally homogenous collection. Only solid analysis and assessment of assortment management in logistical supply systems in foundry plants of particular assortment groups allows to lower the supply costs significantly. In the article the analysis and assessment of the newest implemented optimising algorithms are presented in the process stock management of selected material groups used in a production process of a chosen foundry plant. A practical solution to solve a problem of rotary stock cost minimisation is given as well as of costs while creating a stock with the usage of economical volume and value of order.
\end{abstract}

Keywords: Computer support of casting production, Supply logistics in a foundry plant

\section{Introduction}

Everyday practise shows that having rational basis assessment and costs optimising of logistic processes connected with supply accomplishing, which stands for supply chains in foundry plants, is a process that is characterised by a rather large complexity. The proper solution to these problems requires considering all implemented in this field activities, proper placing in various reference cross-sections and different systematic and transforming activities in order to create totally homogonous collections. Only solid analysis and assessment of assortment management in logistical supply systems in foundry plants of particular assortment groups allow to lower the supply costs significantly [1, $2,4]$. Management methods of material stocks for production in enterprises are usually treated as separate for each ordered assortment alone. Based on practical experience it may be stated that in some peculiar cases much better solution, in case of stocks cost optimisation, will be the implementation of algorithms, which are connected with separate assortments groups. Among the most important factors of such approach based on assortment grouping and subjecting them to common procedure of creating the stock volume may be [1-6]:

- implementing of limits in supply process i.e. precisely defined number of deliveries in particular period, limited stock area or having limited capital;

- supplying at the same supplier or at the supplier close to each other of various assortment items.

\section{Method of research}

Used in own research, method of optimising the rotary stock cost amount minimises the average stock value and consequently the cost of its maintaining. As an advantage of this method it may be treated the possibility of its implementation in cases when the data connected with the amount of service costs of one order and 
the ratio of periodical stock maintenance cost are unknown or they are under great uncertainty. The method requires the knowledge of summary number of deliveries in period under examination. The minimisation of assortment groups stock maintenance costs at first stage is based on the usage of the proportion rule of deliveries quantity of a defined assortment item to a square root of planned deliveries in a given period.

The method of costs minimisation and of assortment groups stock maintenance at the following stages can be proceeded with the usage of the cost minimisation through the orders grouping with the economical value of an order. The method based on costs minimisation may be used through the correction of economical order value and the number of deliveries for ordered items, per each delivery $[1,2]$.

\section{The minimisation of stock cost}

\subsection{Usage of a coverage constant}

The examined foundry plant produces the high quality malleable, ductile cast iron moulds and malleable weldable cast iron. These moulds are used in the energy industry (wheel covers, hangers, boats), automotive (mufflers, engine base, wing hubs), rail (bolts), mining (jaws, spreaders, sprinkles nozzles) or in building industry (joints, nuts, alloys). The foundry plant purchases the material necessary for a production process at three main suppliers: A, B i C. The planned amounts of annual demand on particular material $P P_{i}$ (column D - Fig. 1) was obtained by the usage of various forecast methods.

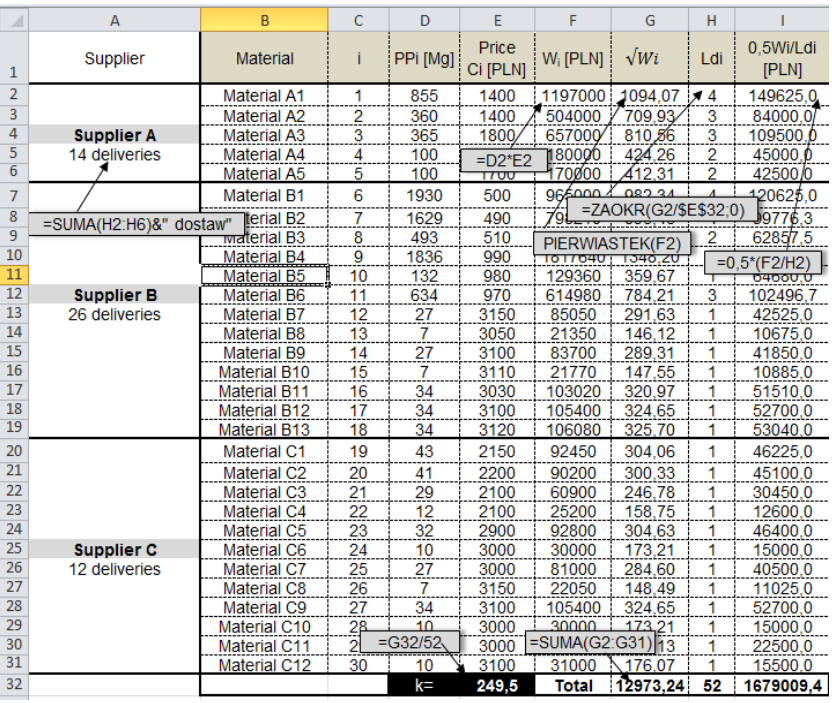

Fig.1. Optimisation of rotary stock cost amount (own data)

Deliveries to the foundry plant are proceeded once a month, which gives $\sum L d_{i}=52$ of delivery per year. After filling unit prices of all materials $C_{i}$ (column $\mathrm{E}-$ Fig.1) the amounts of planned deliveries were calculated $W_{i}$ by multiplying $C_{i}$ with $P P_{i}$ (column F - Fig.1).

At the following stage the summary value of square roots was indicated from the value of planned deliveries of examined assortment group $\sum \sqrt{W i}$ (cell G32 - Fig.1), and dividing it by the total number of deliveries $\sum L d i$ the value of so called coverage constant value $k$ was calculated (cell E32 - Fig.1). By dividing the values of planned deliveries root $\sqrt{W i}$ for each material item by the coverage constant value $k$ the number of deliveries was calculated Ldi (column $\mathrm{H}$ - Fig. 1).

At the final stage the summary average stock value was calculated $S W Z$ (cell I32 - Fig. 1) according to the relation:

$S W Z=\frac{1}{2} \sum_{i=1}^{n} \frac{W_{i}}{L d_{i}}$

To gain the lowest stock value $S W Z$ equals 1679009,4 PLN Suppliers A, B and C should perform in examined periods following: 14, 26 and 12 deliveries while these 52 deliveries should be performed for every mould assortment items with the assigned structure.

\subsection{Usage of economical order value}

The method of cost minimising and assortment groups stock maintenance based on the order supply may be used when the amount of order costs are known as well as of accomplishing one delivery of each assortment, which means the costs connected with accomplishment of one delivery with acceptance to a warehouse $K u_{i}$ (column Q - Fig. 2) and the amount of ratio of stock maintenance cost in particular period $r \%$. (cell P35 - Fig.2). Next for each item cost of stock creating was assigned $K T z_{\mathrm{i}}$ (column S - fig. 2) dividing the product $P P_{i}$ by $K u_{i}$ by $E W Z_{i}$.

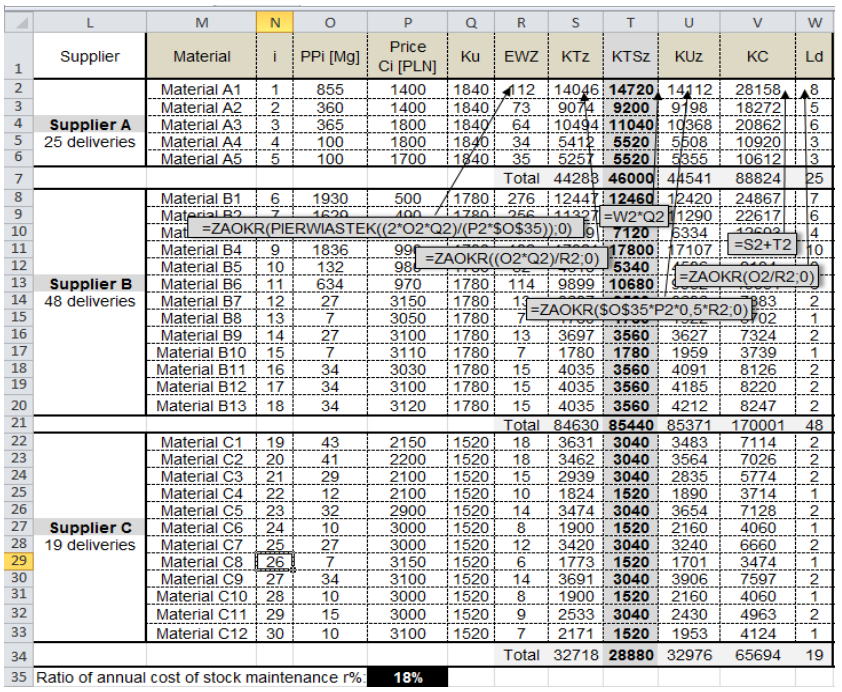

Fig. 2. Assessing costs of stock maintaining and completing for individual assortment ordering (own data)

At first for each assortment the economical value of order was calculated (column R - fig. 2) according to the formula: 
$E W Z_{i}=\sqrt{\frac{2 \cdot P P_{i} \cdot K u_{i}}{C_{i} \cdot r \%}}$

The cost of stock maintenance $K U z_{i}$ (column U - Fig. 2) was calculated as a half of the product of stock maintenance ratio cost $r \%$, of unit price $C_{i}$ and the economical order amount $E W Z_{i}$. The size of total costs $K C_{i}$ for each item (column V - Fig. 2) were the sum of costs of creating $K T z_{i}$ and maintaining stock. $K U z_{i}$. The corrected number of deliveries $L D_{i}$ (column W-Fig. 2) were the quotient of the amount of planned demand $P P_{i}$ and economical size of order $E W Z_{i}$. At the final stage the total number of deliveries was calculated as well as the summary costs of stock creating and maintaining separately for each of three suppliers.

Additionally for each assortment a corrected value of stock creating costs $K T S z_{\mathrm{i}}$ (column T - Fig. 2) multiplying the corrected number of deliveries $L D_{i}$ by $K U_{i}$.

The implemented at this stage method of stock cost minimising is based on orders grouping by using the order economical value $E W a r Z$, which may be treated as a common relative value for all assortments. The order economical value $E W a r Z_{i}$ for each assortment makes the product of order economical value $E W Z_{i}$ and the price $C_{i}$. At first for each of the suppliers a single delivery and order cost was assigned - so called group cost of stock completing that consists of common order of all materials and individual costs of acceptance to the warehouse of each item $K U_{A}, K U_{B}$ or $K U_{B}$ (cells AC7, AC21 and AC34Fig. 3). Next, for each material the value of projected demand was assigned $\mathrm{PWP}_{\mathrm{I}}$ (column AG - Fig. 3) and for each Supplier $P W P_{A}, P W P_{B}, P W P_{C}$ (cells AG7, AG21 and AG34 - Fig. 3).

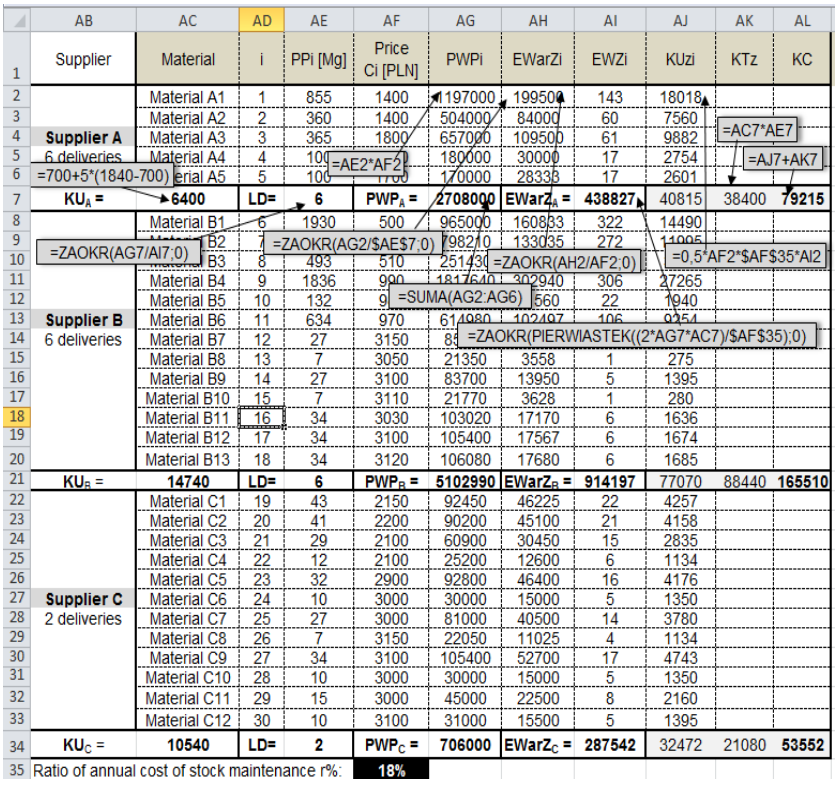

Fig. 3. Assessment of the maintenance and stock completing costs for group assortment orders (own data)

The group order economical value for Supplier A was assigned according to relation:
$E W a r Z_{A}=\sqrt{\frac{2 \cdot P W P_{A} \cdot K U_{A}}{r \%}}$

In similar way order economical values were assigned for the rest of Suppliers (cells AI7, AI21 and AI34 - Fig. 3).

The values were used to indicate the optimal number of deliveries for particular Suppliers $L D_{A}, L D_{B}$ and $L D_{C}$ (cells AE7, AE21 and AE34 - Fig. 3). The order economical value for each material $E W a r Z_{i}$ was achieved by dividing projected demand values $P W P_{i}$ by the number of deliveries (column $\mathrm{AH}-$ Fig. 3 ). By dividing $E W a r Z_{i}$ by $C_{i}$ the order economical value for each material was achieved $E W Z_{i}$ (column AI - Fig. 3). The size of stock maintenance costs for particular materials $K U z_{i}$ (column AJ - Fig. 3) was calculated according to the relation:

$K U z_{i}=\frac{1}{2} C_{i} \cdot E W Z_{i} \cdot r \%$

The costs of stock creating for each Supplier KTz (cells AK7, AK21 and AK34 - Fig. 3) were calculated by multiplying quantity of deliveries $L D$ (cells AE7, AE21 and AE34 - Fig. 3) performed by a particular supplier and the group cost of stock completing that consists of a common order for all items and individual costs of acceptance to the warehouse of each item $K U$ (cells AC7, AC21 and AC34 - Fig. 3).

At the final stage the overall cost of stock creating and maintenance was calculated for the following suppliers $K C_{A}, K C_{B}$ and $K C_{C}$ (cells AL7, AL21 and AL34 - Fig. 3).

\section{Summary and conclusions}

The minimisation method of the rotary stock maintenance cost, with the assumption that the cost of rotary stock completing is constant and it results from determiners or outside limitations, allows the rational formation of assortment items group stocks.

Figure 4 presents the comparison of costs amounts of stock creating $K T_{Z}$, (Fig. 4), costs of stock maintenance $K U_{Z}$ (Fig. 5) and summary costs $K C$ stock creating and maintenance (Fig. 6) for individual and group orders including deliveries from a particular supplier.

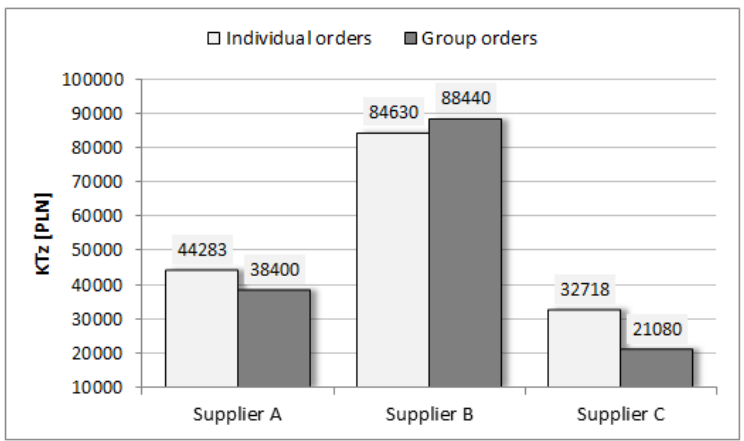

Fig. 4. Comparison of stock creating costs amounts $K T_{Z}$, for individual and group orders (own data) 


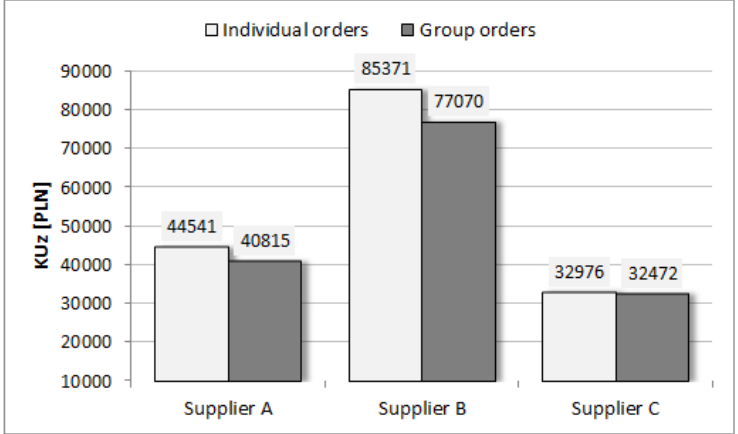

Fig. 5. Comparison of stock maintenance costs amounts $K U_{Z}$ for individual and group orders (own data)

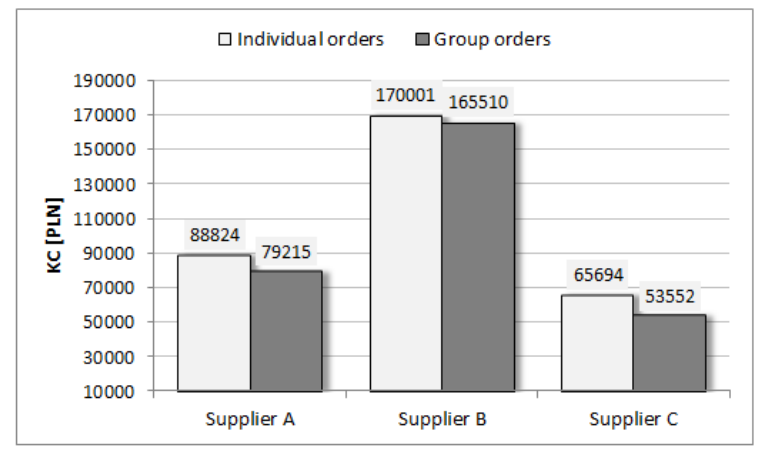

Fig. 6. Comparison of summary costs of stock creating and maintenance $K C$ for individual and group orders (own data)

It may be concluded that in case of group orders the summary decrease in stock creating costs $K T_{Z}$ equals about 13700 PLN, however the decrease in stock maintenance costs $K U_{Z}$ exceeds 12500 PLN. The total cost $K C$ of stock creating and maintenance of the examined assortment group is, in case of a group (assortment in division for a supplier) ordering, lower by over 26000 PLN, in comparison to individual orders.

The minimising of stock creating and maintenance costs based on stock grouping with the usage of order economical value in comparison to the method based on individual assortment orders allows to achieve, during the production supply process of the examined foundry, the financial profits.

Taking into account the achieved results at the following stage it should be considered if all of the materials should be ordered at the same pace, it means that some of them do not have to be delivered in each of the deliveries.

\section{References}

[1] Krzyżaniak, S. (2002). Basis of Resources Management in Examples. Poznań: Ed. Institute of Logistics and Storage. (in Polish).

[2] Szymszal, J., Lis, T., Przondziono, J., Nowacki, K. \& Kliś J. (2013). Optimising a Model of Minimum Stock Level Control and a Model of Standing Order Cycle in Selected Foundry Plant. Archives of Foundry Engineering. 13(3), 87-100.

[3] Szymszal, J., Gajdzik, B. \& Piątkowski, J. (2009). Logistics Enterprise. Gliwice: Ed. Silesian University of Technology. (in Polish).

[4] Sarjusz-Wolski, Z. (2000). Stock controlling in an enterprise. Warszawa: Ed. PWE (in Polish).

[5] Grzybowska, K. (2009). Basis of logistics. Warszawa: Ed. Difin (in Polish).

[6] Pisz, I., Sęk, T., Zielecki, W. (2013). Logistics Enterprise. Warszawa: PWE (in Polish). 